\title{
Article \\ Comprehensive Somatic Copy Number Analysis Using Aqueous Humor Liquid Biopsy for Retinoblastoma
}

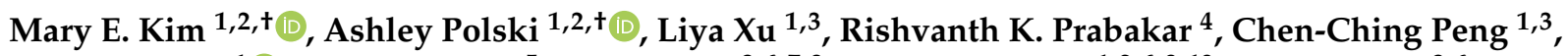 \\ Mark W. Reid ${ }^{1}$ (D), Rachana Shah ${ }^{5}$, Peter Kuhn ${ }^{3,6,7,8}$, David Cobrinik 1,2,6,9,10, James Hicks ${ }^{3,6}$ \\ and Jesse L. Berry $1,2,6,10, *$ D
}

check for updates

Citation: Kim, M.E.; Polski, A.; Xu, L.; Prabakar, R.K.; Peng, C.-C.; Reid, M.W.; Shah, R.; Kuhn, P.; Cobrinik, D.; Hicks, J.; et al. Comprehensive Somatic Copy Number Analysis Using Aqueous Humor Liquid Biopsy for Retinoblastoma. Cancers 2021, 13, 3340. https://doi.org/ 10.3390/cancers 13133340

Academic Editor: Simon Saule

Received: 31 May 2021

Accepted: 30 June 2021

Published: 3 July 2021

Publisher's Note: MDPI stays neutral with regard to jurisdictional claims in published maps and institutional affiliations.

Copyright: (c) 2021 by the authors. Licensee MDPI, Basel, Switzerland. This article is an open access article distributed under the terms and conditions of the Creative Commons Attribution (CC BY) license (https:// creativecommons.org/licenses/by/ $4.0 /)$.
1 The Vision Center at Children's Hospital Los Angeles, Los Angeles, CA 90027, USA; maryekim@usc.edu (M.E.K.); ashley.polski@usc.edu (A.P.); lixu@chla.usc.edu (L.X.); ppeng@chla.usc.edu (C.-C.P.); mreid@chla.usc.edu (M.W.R.); cobrinik@usc.edu (D.C.)

2 USC Roski Eye Institute, Keck School of Medicine of the University of Southern California, Los Angeles, CA 90033, USA

3 Department of Biological Sciences, Dornsife College of Letters, Arts, and Sciences, University of Southern California, Los Angeles, CA 90007, USA; pkuhn@usc.edu (P.K.); jameshic@usc.edu (J.H.)

4 Department of Molecular and Computational Biology, University of Southern California, Los Angeles, CA 90007, USA; kaliappa@usc.edu

5 Cancer and Blood Disease Institute at Children's Hospital Los Angeles, Los Angeles, CA 90027, USA; rachana@usc.edu

6 Norris Comprehensive Cancer Center, Keck School of Medicine, University of Southern California, Los Angeles, CA 90033, USA

7 Department of Aerospace and Mechanical Engineering, Viterbi School of Engineering, University of Southern California, Los Angeles, CA 90007, USA

8 Department of Biomedical Engineering, Viterbi School of Engineering, University of Southern California, Los Angeles, CA 90007, USA

9 Department of Biochemistry and Molecular Medicine, Keck School of Medicine, University of Southern California, Los Angeles, CA 90033, USA

10 The Saban Research Institute, Children's Hospital Los Angeles, Los Angeles, CA 90027, USA

* Correspondence: jesse.berry@med.usc.edu; Tel.: +1-323-442-6335

$\dagger$ These authors contributed equally to this paper.

Simple Summary: Aqueous humor (AH) liquid biopsy is an enriched source of cell-free circulating tumor-derived DNA for retinoblastoma (RB). The use of this AH liquid biopsy allows for genomic analysis of eyes in the absence of tumor tissue. Development of this platform was critical because direct tumor biopsy is prohibited in RB due to risk of extraocular tumor spread. In this retrospective study, we provide comprehensive, whole-genome analysis of the somatic copy number alterations (SCNAs) in 68 eyes of 64 RB patients. We show that the prevalence of specific SCNAs differ between eyes that required immediate enucleation (surgical removal) and eyes that were attempted to be saved but subsequently failed treatment, requiring secondary enucleation. Increases in chromosomal instability, or higher number of broad genomic alterations, predict higher risk clinical and biomarker features in these eyes. Prospective analyses are needed to further determine the clinical relevance and application of these findings.

Abstract: Aqueous humor (AH) liquid biopsy has been established as a surrogate tumor biopsy for retinoblastoma (RB). Previous AH studies have focused on highly recurrent RB somatic copy number alterations (SCNAs) including gain of 1q, 2p, 6p, and loss of 13q and 16q. In this retrospective study, we provide a comprehensive, whole-genome analysis of RB SCNAs and evaluate associated clinical features for 68 eyes of $64 \mathrm{RB}$ patients from whom AH was obtained between December 2014 and October 2020. Shallow whole-genome sequencing of AH cell-free DNA was performed to assess for SCNAs. The prevalence of specific non-highly recurrent SCNAs, such as $20 \mathrm{q}$ gain and $8 \mathrm{p}$ loss, differed between primarily and secondarily enucleated eyes. Increases in chromosomal instability predict more advanced seeding morphology $(p=0.015)$; later age of diagnosis $(p<0.0001)$; greater odds of an endophytic tumor growth pattern (without retinal detachment; $p=0.047$ ); tumor heights $>10 \mathrm{~mm}(p=0.09)$; and containing 6p gain, a biomarker of poor ocular prognosis $(p=0.004)$. 
The AH liquid biopsy platform is a high-yield method of whole-genome RB SCNA analysis, and SCNAs are associated with numerous clinical findings in RB eyes. Prospective analyses are encouraged to further elucidate the clinical relevance of specific SCNAs in RB.

Keywords: retinoblastoma; aqueous humor; liquid biopsy; cell-free DNA; circulating tumor DNA; SCNA; prognostic biomarker; precision oncology

\section{Introduction}

Retinoblastoma (RB), a cancer of the developing retina in infants and toddlers, is the most common pediatric intraocular malignancy [1] and accounts for $1 \%$ of childhood cancer mortality [2]. RB tumorigenesis has been extensively studied. In the vast majority of cases analyzed, biallelic inactivation of the tumor suppressor gene $R B 1$ results in development of a premalignant retinoma [3-7], and additional mutational or epigenetic events may promote progression of a retinoma to fully malignant $\mathrm{RB}[3,8]$. By activating oncogenes and inactivating tumor suppressor genes, somatic copy number alterations (SCNAs) are thought to contribute to subsequent RB progression [3,9-13]. However, some tumors are negative for SCNAs or these genomic alterations are sub-clonal, suggesting a complicated series of heterogenous events for tumorigenesis in RB. As most studies have been done on tissue from enucleated eyes, we know very little about these events in less advanced eyes and additionally what new alterations may form under selective therapeutic pressure during attempts to salvage the eye.

Although highly recurrent RB SCNAs-gains on 1q, 2p, 6p; losses on 13q and 16q; and focal MYCN amplification - are well established and documented [10,11,14-16], these analyses were performed exclusively on tumor tissue from enucleated eyes. This was due to previous inability to biopsy RB for risk of extraocular seeding [17,18]. Our group addressed this limitation by demonstrating that aqueous humor $(\mathrm{AH})$ can be safely extracted and is a rich source of circulating tumor DNA (ctDNA) within the AH [19-21]. Using this platform, we have been able to establish relationships between specific genomic alterations and ocular prognosis that could not previously be evaluated in tumor tissue from enucleated eyes only. For example, by comparing genomic profiles of ctDNA between the AH of eyes that were cured and salvaged versus those that required enucleation, we were able to demonstrate that the highly recurrent RB SCNA 6p gain is a biomarker of poor prognosis, portending an increased risk for treatment failure and enucleation [20,22]. Similarly, focal $M Y C N$ amplification is known to cause aggressive disease in wildtype $R B 1$, and in a small cohort we have shown that it is a biomarker of poor prognosis for globe salvage regardless of RB1 status [20,22]. This was the first time that any RB SCNA was able to be connected to clinical ocular outcomes for eyes actively undergoing salvage therapy, and this association was facilitated by the AH liquid biopsy platform.

While past studies focused on highly recurrent SCNAs, the aim of the present study was to employ the AH liquid biopsy to comprehensively characterize SCNAs that exist genome-wide in RB eyes actively undergoing treatment. Previous whole-genome analyses of RB SCNAs were limited to tumor tissue from enucleated eyes, so little was known about the genomic landscape of tumors in less advanced, salvaged eyes or new alterations identified during therapy $[10,11,14-16]$. Additionally, although our group has since used the $\mathrm{AH}$ liquid biopsy to identify RB SCNAs in both salvaged and enucleated eyes, these studies focused primarily on a limited subset of highly recurrent SCNAs and did not evaluate for other less common SCNAs that might also be contributing to RB tumorigenesis, seeding, treatment failure, or progression of disease [19-26]. Herein we present a comprehensive (whole-genome) analysis of RB SCNAs using the AH liquid biopsy. With this minimally invasive platform, we hope to further elucidate the relationship between SCNAs and RB progression, disease severity, and prognosis for eye salvage. 


\section{Materials and Methods}

This research was conducted under Children's Hospital Los Angeles (CHLA) Institutional Review Board approval and adhered to the tenets of the Declaration of Helsinki. Written informed consent was obtained from the legal guardians of all participants.

This study included all patients diagnosed with RB between December 2014 and October 2020 at CHLA from whom written parental consent and aqueous humor sample(s) were obtained. Hence, this study includes AH samples that have been analyzed and published previously, in addition to new samples taken after our most recent publications. Case numbers remained consistent with prior studies for comparison purposes [20-22,25,26]. As in previous studies [19-26], liquid biopsy specimens consisted of approximately $100 \mu \mathrm{L}$ $\mathrm{AH}$ taken from the anterior chamber via clear corneal paracentesis for research purposes only. Treatment of all RB patients was carried out in a non-randomized manner per CHLA protocol [27-29], and treating physicians were blinded to the results of $\mathrm{AH}$ analyses. In general, treatment courses include six cycles of systemic chemotherapy (carboplatin, etoposide, and vincristine) or intra-arterial chemotherapy with melphalan, followed by local treatment that can range from targeted laser and cryotherapy to intravitreal chemotherapy injections to treat vitreous seeds [27-29].

The samples evaluated are part of a biorepository of AH samples aimed at understanding whether genomic markers correlate with ocular outcomes and the presence of other clinical features. The timing of the first $\mathrm{AH}$ sample for each patient depended on the IRB approval governing our research at the time and was either (1) at diagnosis $(9 / 68,13 \%),(2)$ at the end of systemic chemotherapy $(4 / 68,6 \%)$, (3) end of intra-arterial melphalan treatment $(1 / 68,1 \%)$, (4) with intravitreal melphalan injection $(33 / 68,49 \%)$, (5) with enucleation $(19 / 68,28 \%)$, or (6) with bevacizumab injection $(1 / 68,1 \%)$. Thirty-four eyes $(50 \%)$ had more than one sample taken over the course of treatment but only the first sample taken was included in this comprehensive analysis, with the exception of case 39 wherein the first AH sample had a tumor fraction below the threshold for SCNA detection $(<5 \%)$ so the second AH sample was used.

A clinical database regarding clinical presentation, patient outcomes, response to therapy, recurrence, any complications from AH sampling, metastasis, death and follow-up is maintained and updated prospectively, in real time during each examination under anesthesia or clinic visit, per IRB approved protocol; once genomic analyses were completed it was reviewed for clinical information. Information collected from the database herein includes International Intraocular Retinoblastoma Classification (IIRC; a system that classifies tumors confined to the ocular space into five groups of increasing severity from A to E based on clinical features) [30], vitreous seeding morphology, and intraocular tumor growth pattern. Germline RB1 mutation status was identified per routine clinical leukocyte testing and obtained from the medical record as well; this is not an additional research protocol. Primary clinical endpoints included eye salvage (the ability to save the eye using standard chemotherapeutic modalities) versus enucleation (surgical removal of the eye). Procedure and protocol for primary and secondary enucleation at our institution have been published previously; primary enucleation is done without any other therapy and secondary enucleation is for intraocular relapse after attempts to save the eye [27-29]. One eye in this study (Case 48) received one cycle of intra-arterial chemotherapy and developed massive tumor growth less than 1 month from diagnosis; due to the timing, this was classified as primary enucleation.

$\mathrm{AH}$ samples were processed and stored according to established protocols that are detailed in previous publications [19,31,32]. Briefly, samples were stored on dry ice immediately following extraction and placed into a $-80{ }^{\circ} \mathrm{C}$ freezer within an hour after extraction. Samples underwent cell-free DNA (cfDNA) isolation using the QIAamp Circulating Nucleic Acid Kit (Qiagen, Germantown, MD, USA) within $72 \mathrm{~h}$ of extraction from the eye (often the same day). CfDNA was constructed into whole genome libraries using the QIAseq Ultralow Input library kit (Qiagen, Germantown, MD, USA) within $72 \mathrm{~h}$ of cfDNA isolation. Shallow whole genome sequencing was performed on these constructed 
libraries at $0.3 \times$ depth for copy number profiling within 1 month of library preparation. SCNAs were considered present at $20 \%$ deflection from a baseline human genome; the bioinformatics protocols by Baslan et al. used on the AH platform have been previously published [20,31,32].

Genomic instability was calculated as the sum of the absolute values of Log2transformed expression ratios for all segment bins, excluding chromosome $\mathrm{X}$ and $\mathrm{Y}$, and represented as the sum deviation from the median. Higher values indicate greater instability.

Mann-Whitney U, Fisher's exact, logistic regression, and Poisson regression tests were used to examine the relationship between SCNAs and clinical findings. All analyses were conducted using Stata/SE 14.2 (StataCorp LLC, College Station, TX, USA).

\section{Results}

\subsection{Patient Demographics and Clinical Outcomes}

Sixty-four patients were included in the study; four patients with bilateral disease had both eyes sampled, so a total of 68 eyes were included in the analysis. No patients dropped out or withdrew consent over the study period. Demographics, clinical features, and SCNA findings of all participants are summarized in Figures S1 and S2. The median age at diagnosis for all patients was 15 months. Twenty-nine patients were RB1 positive $(45 \%)$, while the remaining 35 patients $(55 \%)$ were negative for $R B 1$ germline mutation. Of all eyes, the most commonly diagnosed IIRC group [30] was D $(46 / 68,68 \%)$, although less advanced (Groups B and C) eyes were also included.

Thirty-three eyes were enucleated (49\%; 16 primarily; 17 secondarily after chemotherapy) and 35 eyes (51\%) were salvaged. No patients had complications secondary to $\mathrm{AH}$ sampling, including infection, iris trauma, synechiae, hyphema, or cataract. No child developed extraocular disease or metastatic disease throughout the follow-up period. Clinical follow-up from diagnosis to final evaluation ranged from 6 to 84 months (median, 33.5 months).

\subsection{Whole-Genome RB SCNA Analysis}

As in previous studies [19-26], the most common RB SCNAs included highly recurrent $6 \mathrm{p}$ gain (33 eyes, $48.5 \%)$, 1q gain (33 eyes, $48.5 \%$ ), 16q loss ( 28 eyes, $41.2 \%)$, $2 \mathrm{p}$ gain (11 eyes, $16.2 \%$ ), and $13 q$ loss ( 8 eyes, $11.8 \%$ ). The most common non-highly recurrent RB SCNAs were $12 p$ loss ( 8 eyes; $11.8 \%), 16 p$ loss ( 8 eyes; $11.8 \%), 5 p$ gain $(7$ eyes; $10.3 \%)$, $17 q$ gain ( 6 eyes; $8.8 \%), 18 q$ gain ( 6 eyes; $8.8 \%), 17 p$ loss ( 5 eyes; $7.4 \%), 20 q$ gain ( 5 eyes; $7.4 \%$ ), and $22 \mathrm{p}$ gain (5 eyes; $7.4 \%$ ). Eyes with a $6 \mathrm{p}$ gain at or above an amplitude of 1.5 ratio to the median showed significantly more chromosomal instability (mean 507.04, SD 231.95 sum deviation from the median) than eyes without a 6p gain (mean 272.19, SD 263.22 sum deviation from the median; $p=0.0002$ ). A composite SCNA frequency plot for all eyes can be seen in Figure 1.

Focal MYCN amplification was present in four eyes (6.3\%; Cases 3, 10, 31, and 48); the presence of $M Y C N$ amplification does not necessarily denote a $M Y C N$-driven tumor which clearly Case 10 is not (germline RB1 mutation present). All four of these eyes were enucleated (Table 1). Two eyes (Cases 3 and 48) displayed SCNAs in addition to focal MYCN amplification in both the AH and matched tumor tissue, while the other two eyes (Cases 10 and 31) only displayed MYCN amplification. There was no somatic RB1 mutation identified in either the $\mathrm{AH}$ or the tumor for any of these cases; on histopathologic review, none of these eyes had characteristic features of primary MYCN amplified retinoblastoma tumors [14]. 


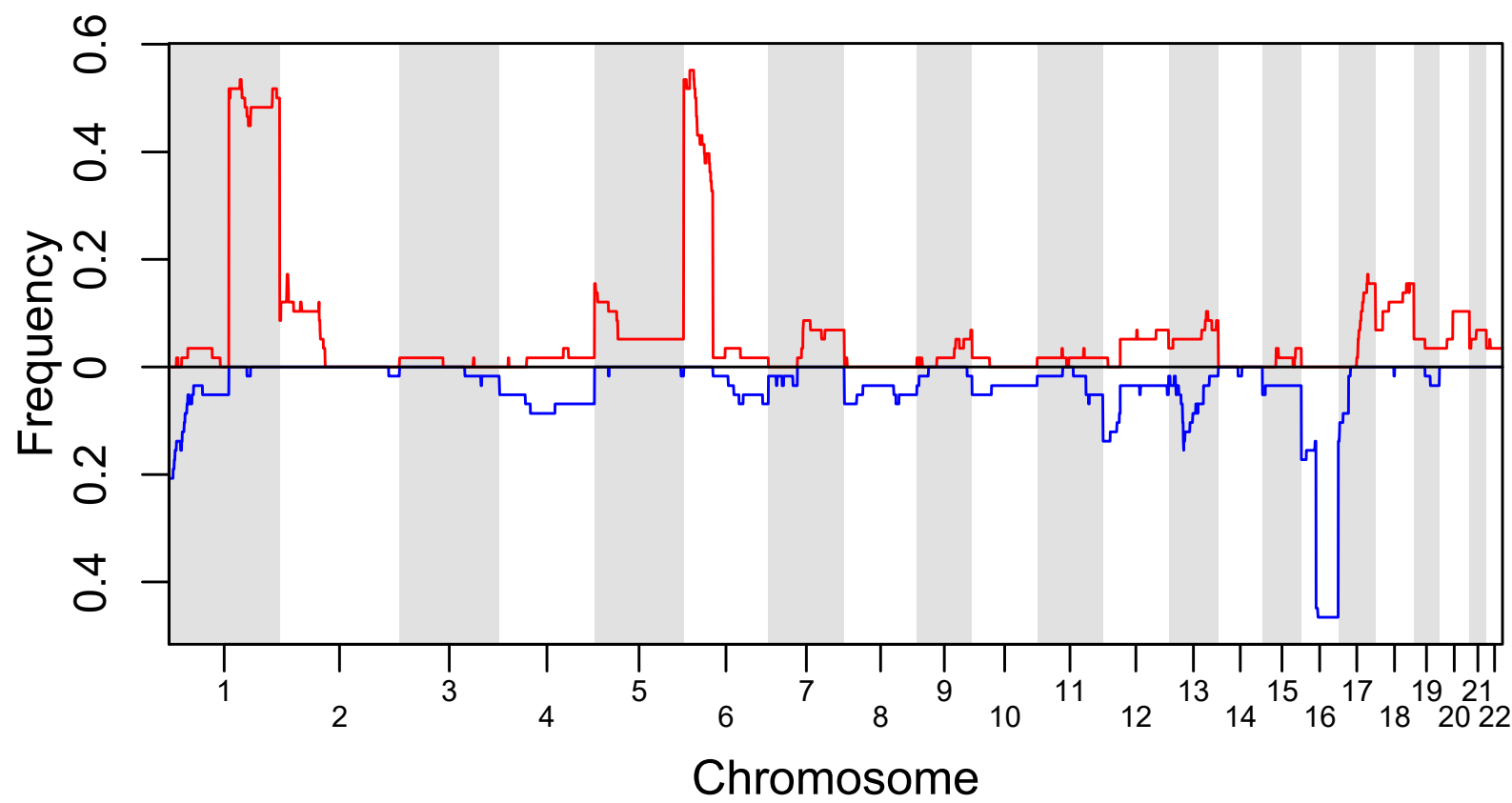

Figure 1. Composite SCNA plot for all eyes included in our study. Gains are represented by the red line and losses are represented by the blue line. Besides previously determined highly recurrent RB SCNAs of 1q, 2p, and 6p gain as well as $16 q$ loss, non-highly recurrent SCNAs were also seen. The most common were 12p loss, 16p loss, $5 p$ gain, 17q gain, 18q gain, $17 \mathrm{p}$ loss, 20q gain, and 22p gain.

Table 1. Clinical and genomic characteristics of $M Y C N$ amplification tumors.

\begin{tabular}{|c|c|c|c|c|c|c|c|c|}
\hline Case & Laterality & $\begin{array}{c}\text { Age at } \\
\text { Diagnosis } \\
\text { (months) }\end{array}$ & $\begin{array}{c}\text { Germline } \\
\text { RB1 } \\
\text { Mutation }\end{array}$ & $\begin{array}{l}\text { Timing of } \\
\text { Enucleation }\end{array}$ & Other SCNAs & $\begin{array}{c}\text { Somatic } \\
R B 1 \\
\text { Mutation } \\
\text { in AH }\end{array}$ & $\begin{array}{c}\text { Somatic } \\
R B 1 \\
\text { Mutation } \\
\text { inTumor }\end{array}$ & $\begin{array}{c}\text { Distinct } \\
\text { Histologic } \\
\text { Features } \\
\text { for } M Y C N \\
\text { Amplified } \\
\text { Tumors * }\end{array}$ \\
\hline 3 & Unilateral & 38 & Negative & Primary & $\begin{array}{l}1 \mathrm{q} \text { and } 6 \mathrm{p} \text { gain, } 16 \mathrm{p} \\
\text { and } 16 \mathrm{q} \text { loss }\end{array}$ & None & None & None \\
\hline 10 & Bilateral & 2 & Positive & $\begin{array}{l}\text { Secondary for } \\
\text { persistent seeding }\end{array}$ & None & None & None & None \\
\hline 31 & Unilateral & 9 & Negative & Primary & None & None & None & None \\
\hline 48 & Unilateral & 18 & Negative & Primary & 1q gain & None & None & None \\
\hline
\end{tabular}

* distinct histologic features in $M Y C N$-amplified tumors include large prominent undifferentiated cells with multiple nucleoli, necrosis, apoptosis, and minimal calcification [14].

\subsection{Clinical Correlates of RB SCNAs}

We also aimed to evaluate associations between clinical presentation and genomic instability, measured either as whole integer number of SCNAs present or total deviation from median copy number amplitude. In general, eyes with higher chromosomal instability tended to display more advanced clinical disease. Less advanced IIRC Group B eyes had lower genomic instability ( $n=3$, mean 315.90, SD 347.85 sum deviation from the median) than more advanced eyes IIRC Groups C-E, although this was not statistically significant ( $n=65$, mean 338.82, SD 274.02 sum deviation from the median, $z=-0.34, p=0.73$ ).

In terms of seeding, eyes with either dust or no seeding displayed significantly less chromosomal instability compared to eyes with more advanced seeding morphologies of sphere or cloud ( $p=0.007$; Figure 2A). Sphere seeding was associated with the largest whole integer number of SCNAs, followed by cloud, dust and no seeding, but only the comparison between sphere and no seeding was statistically significant $(p=0.024$; Figure 2B). There was no significant difference in presence or absence of seeding between eyes with or without a $16 \mathrm{q}$ loss $(p=0.46)$. 
A

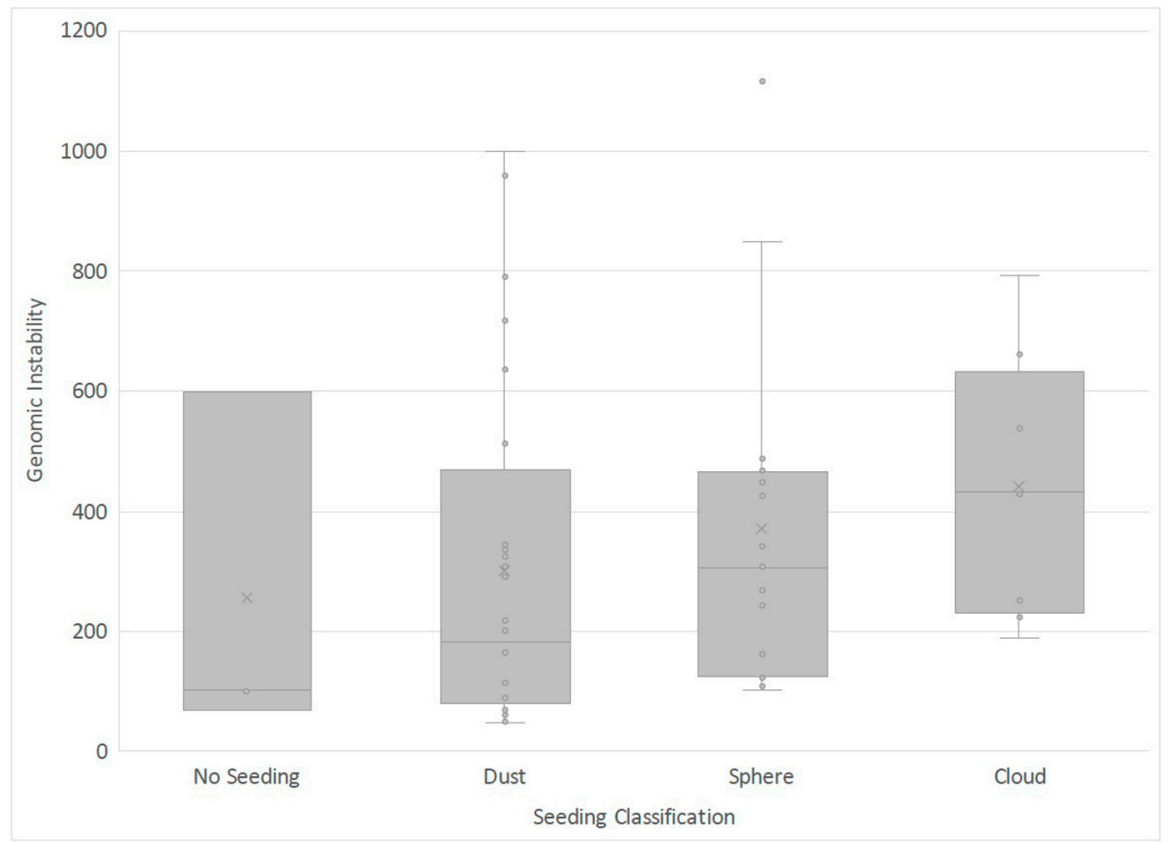

B

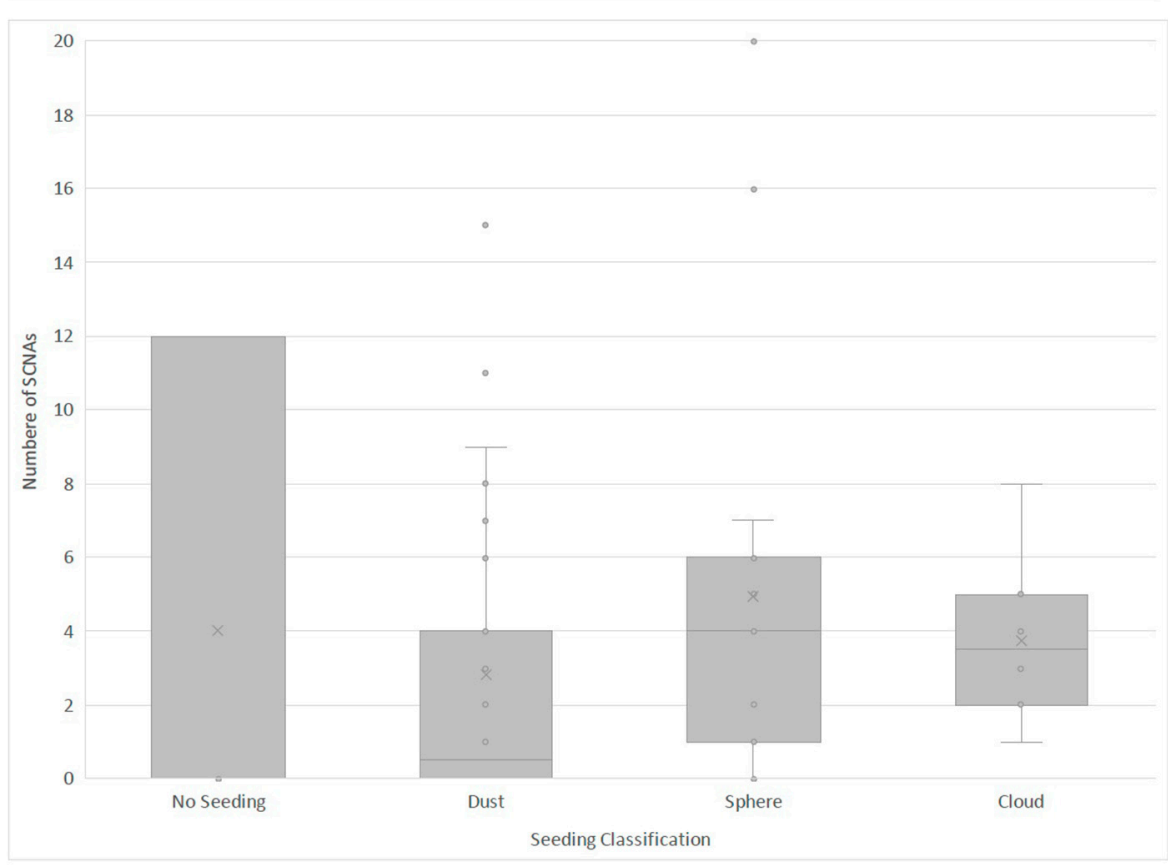

Figure 2. Box and whisker plot showing (A) genomic instability based on seeding classification and (B) integer numbers of SCNAs based on seeding classification. $x$ indicates the median value.

As shown in Figure 3, based on laterality, eyes with unilateral RB displayed significantly more chromosomal instability compared to bilateral RB eyes $(p=0.03)$. This corresponded to a difference in age at diagnosis, with unilateral eyes diagnosed at significantly older ages (mean 19.44 months, SD 12.06) compared to bilateral eyes (mean 12.67 months, SD 10.21, $p=0.022$ ). When run in Poisson regression, the effects of laterality (IRR $=0.69,95 \% \mathrm{CI}=0.40-1.17, p=0.17)$ and its interaction with age (IRR $=1.01$, $95 \% \mathrm{CI}=0.99-1.04, p=0.20)$ were non-significant, leaving age at diagnosis as the predictor of chromosomal instability (IRR $=1.04,95 \% \mathrm{CI}=1.03-1.05, p<0.001$ ). For each month increase in age at diagnosis, the rate at which SCNAs are detected in patients increases 1.04 times. Similarly, there was no significant difference in the genomic instability based on heritability (presence or absence of $R B 1$ germline mutation $(p=0.23)$. 


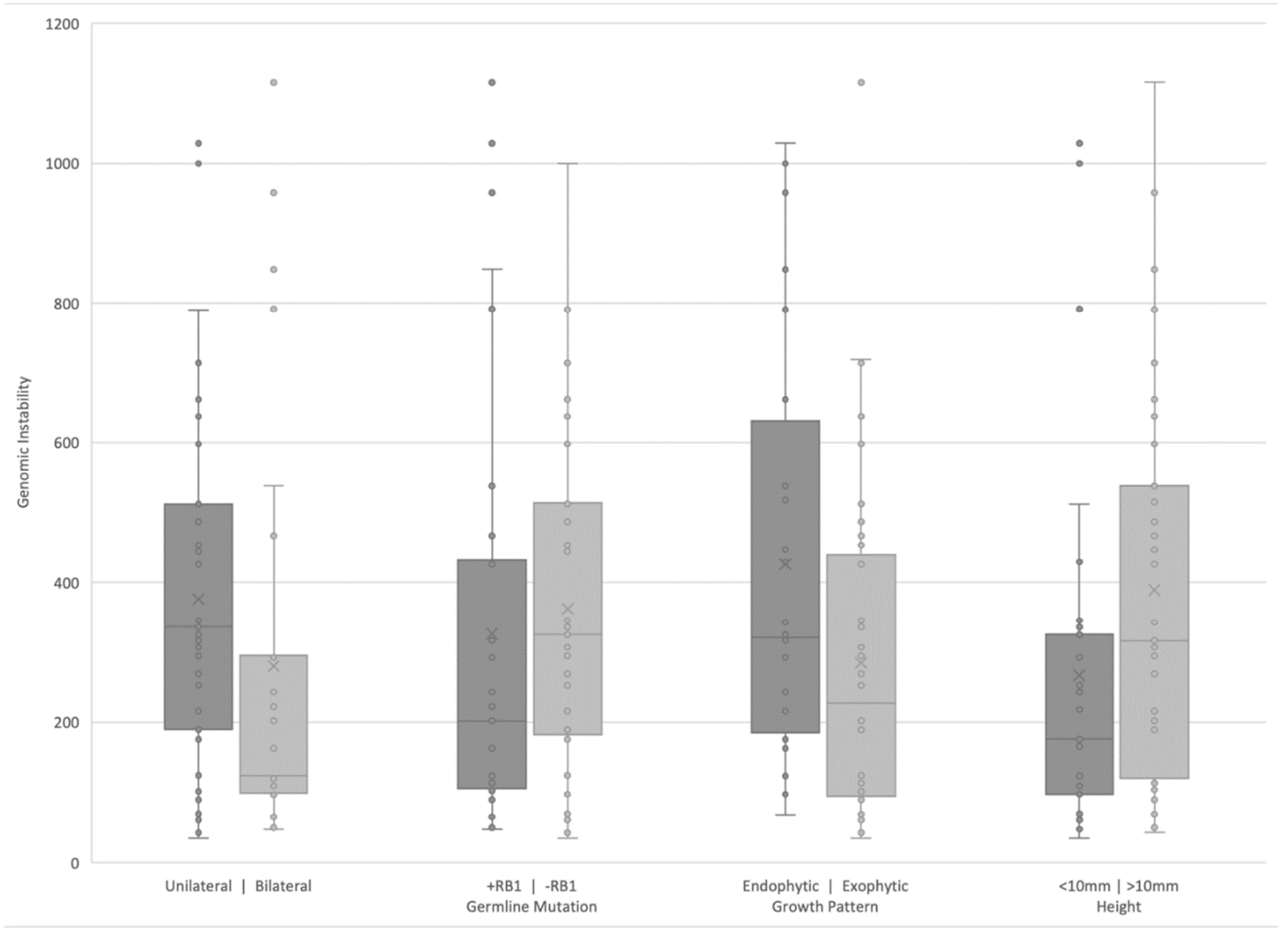

Figure 3. Box and whisker plot showing genomic instability based on laterality, heritability (+ RB1 indicates a germline mutation), growth pattern, and height. $x$ indicates the median value.

Eyes with an endophytic tumor growth pattern (without retinal detachment) displayed significantly more chromosomal instability than an exophytic growth pattern ( $p=0.03$; Figure 3). However, after controlling for the effects of seeding, the effect was no longer significant $(p=0.18)$. Regarding main tumor size, eyes with initial (pre-treatment) tumor height $\geq 10 \mathrm{~mm}$ had marginally greater instability than eyes with initial tumor height $<10 \mathrm{~mm}(p=0.05$; Figure 3).

\subsection{RB SCNAs in Enucleated Eyes}

There was no difference in chromosomal instability between eyes that were treated versus primarily enucleated (treated eyes mean 320.16, SD 295.71 sum deviation from the median; primarily enucleated eyes mean 395.17, SD 186.34 sum deviation from the median; $z=-1.81, p=0.07)$. However, the prevalence of specific non-highly recurrent SCNAs does differ between primarily and secondarily enucleated eyes (Figure 4). For example, four eyes demonstrated 20q gain and three eyes demonstrated $8 p$ loss in the secondary enucleation group; these SCNAs were not seen in the primary enucleation group, and this difference approached significance for 20q gain $(p=0.10)$. 


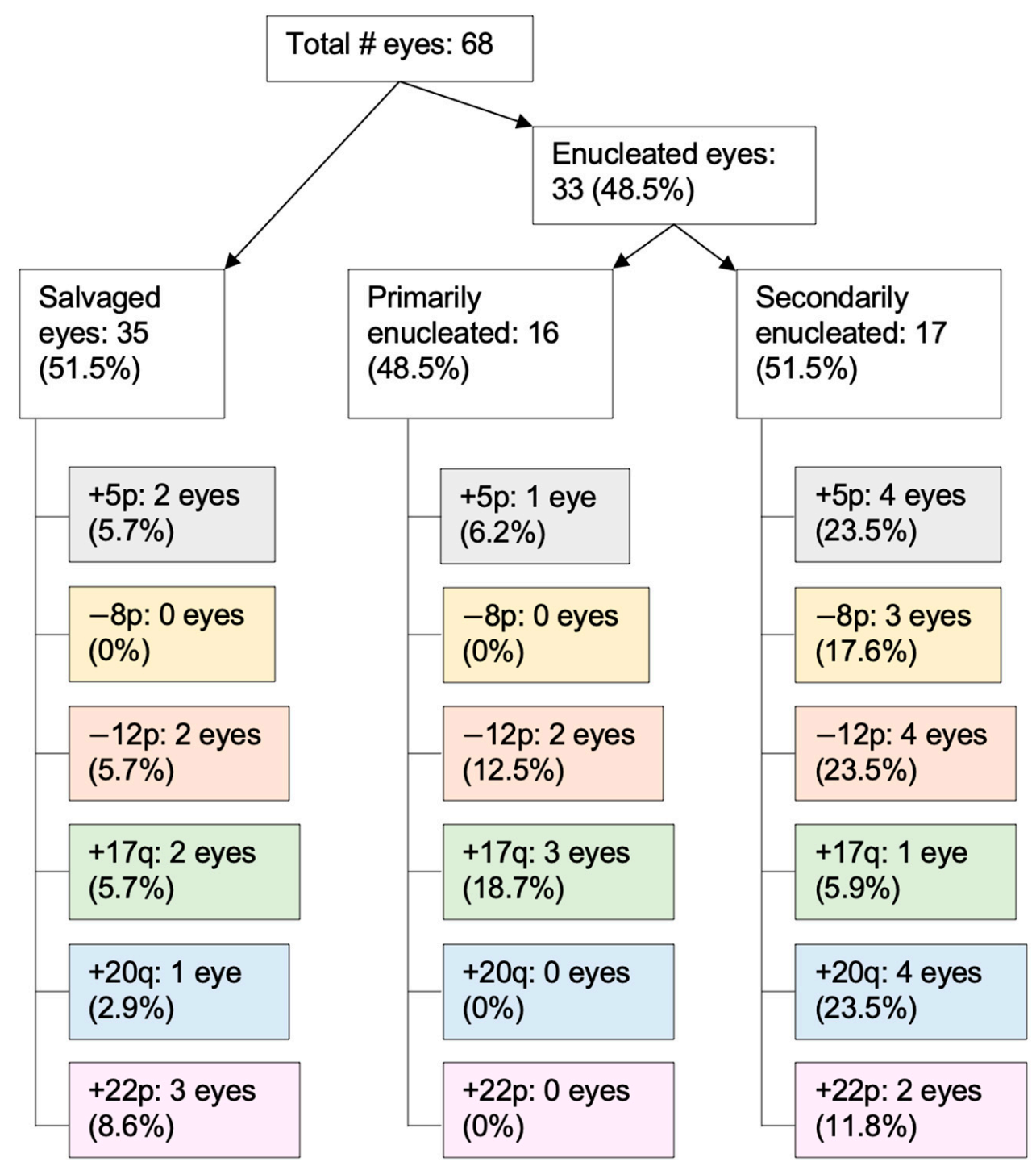

Figure 4. The prevalence of specific non-highly recurrent SCNAs differed between primarily and secondarily enucleated eyes. Note, not all secondarily enucleated eyes had AH sampled prior to enucleation to be used for comparison of new SCNAs.

Of secondarily enucleated eyes, six had AH sampled during conservative management and immediately following enucleation. For these six eyes, AH samples obtained at secondary enucleation had a higher number of SCNAs (mean 5.67, SD 7.17) compared to their corresponding AH samples taken during conservative management (mean 1.00, SD 1.26), and this difference approached statistical significance $(p=0.055)$. Four eyes demonstrated new SCNAs at secondary enucleation that were not present in earlier AH samples (Figure 5). The first samples taken from cases 11, 15, and 17 were during IVM injection, whereas the first sample taken from case 33 was at diagnosis.

There was no significant difference in the age at diagnosis of treated versus primarily enucleated eyes (treated eyes mean 15.6 months, SD 12.5; primarily enucleated eyes mean 20.4, SD 8.5; $z=-1.82, p=0.07)$. 

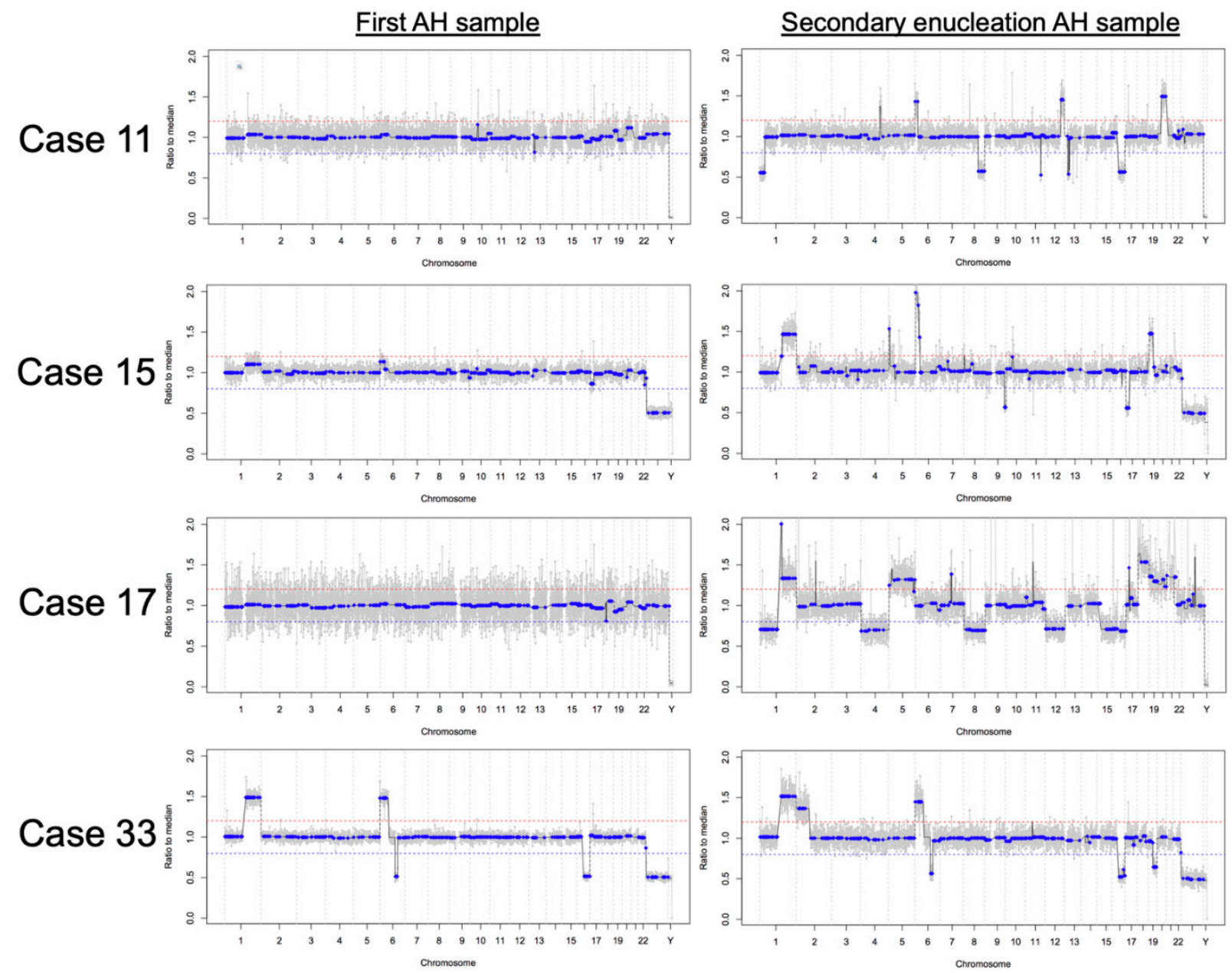

Figure 5. Four eyes demonstrated new SCNAs at secondary enucleation that were not present during conservative management. New SCNAs were as follows: Case 11 (8q loss, 16q loss, 20q gain), Case 15 (1q gain, 6p gain, 17p loss, 19p gain), Case 17 (1p loss, 1q gain, $4 p$ loss, 4q loss, $5 p$ gain, $5 q$ gain, $8 p$ loss, $8 \mathrm{q}$ loss, $12 p$ loss, 12q loss, 15q loss, 16p loss, 16q loss, 18p gain, 18q gain, 19p gain, 19q gain, 20p gain, 20q gain, 21q gain), and Case 33 (2p gain, 19q loss). Other focal changes seen are at the centromeres and not true SCNAs. The first samples taken from cases 11, 13, and 17 were during IVM injection, whereas the first sample taken from case 33 was at diagnosis. Treatment courses for these cases are as follows. Case 11 underwent systemic chemotherapy treatment (six cycles of carboplatin, etoposide, and vincristine (CEV)), followed by four IVM injections over three months for recurrent dust seeding; the eye was enucleated 14 months after diagnosis due to primary tumor recurrence. Case 15 began treatment with three monthly intra-arterial melphalan injections, followed by three weekly IVM injections for dust seeding; the eye was enucleated 22 months after diagnosis due to primary tumor recurrence. Case 17 underwent systemic chemotherapy treatment (six cycles CEV), followed by three IVM injections over one month for recurrent sphere seeding; the eye was enucleated two months later due to primary tumor recurrence. Finally, Case 33 was treated with two cycles of CEV as a bridge and three cycles of intra-arterial melphalan, followed by four IVM injections over six weeks to treat persistent dust seeding; the eye was enucleated six months after diagnosis due to apical tumor recurrence with persistently active seeding despite ongoing therapy.

\section{Discussion}

Herein we present the first comprehensive, whole-genome RB SCNA analysis using the AH liquid biopsy. Although previous genome-wide studies of RB SCNAs were limited exclusively to enucleated tumor tissue [10,11,14-16], the AH liquid biopsy for RB has facilitated the investigation of RB SCNAs in all eyes-including those that are actively undergoing therapy or even treatment-naïve [19-26]. The implementation of this organspecific liquid biopsy allows for evaluation of tumoral information from less advanced eyes (such as Group B eyes), and importantly, with longitudinal sampling of the same eye, the 
potential to detect impactful new genomic alterations that arise under therapeutic pressure. The findings of this and past studies [19-26] suggest that the AH liquid biopsy is a safe and minimally invasive approach to whole-genome SCNA analysis. With additional larger, prospective studies, results from the $\mathrm{AH}$ liquid biopsy may help us better understand the relationships between RB genomics, clinical features, and outcomes.

Although the previously identified highly recurrent RB SCNAs remained the most prevalent among the 68 eyes analyzed here, specific non-highly recurrent RB SCNAs were also seen albeit at far lower rates; this is similar to past publications on tumor tissue $[3,4,8,11,33])$. Identifying candidate genes in these regions is an important next step given that the ultimate goal of characterizing SCNAs is to uncover their role-if any-in the tumorigenesis, disease severity, and treatment response of RB. This has been done for highly recurrent RB SCNAs in enucleated RB tumor samples [3,4,8,11,33]; however, there have been no candidate gene studies performed on non-surgically removed eyes or non-highly recurrent RB SCNAs, and there is little understanding of the evolution of these SCNAs during treatment as tumoral information was previously unattainable until the time of enucleation. Based on comprehensive analyses of SCNAs in pan-cancer cohorts, there are known cancer driver genes within the non-highly recurrent RB SCNA regions that may contribute to RB tumorigenesis [34-36]. For example, within chromosome 5p, amplified in $10 \%$ of eyes studied here, the Telomerase Reverse Transcriptase (TERT) gene has been identified as an oncogene [34-36]. TERT is responsible for stabilizing telomere length and when amplified, prevents the permanent growth arrest phase that cells normally enter once telomeres become too short, ultimately leading to uncontrolled proliferation [37-40]. TERT gains have been previously identified in three of 83 enucleated $R B$ tumors examined by targeted sequencing [41]. Another candidate gene is Ataxin 2 Binding Protein 1 ( $A 2 B P 1$, also known as RBFOX1) located in the chromosome 16p [35,36], which was suppressed in $12 \%$ of the eyes analyzed here and is frequently a result of whole chromosome 16 loss in RB [11]. A2BP1 interacts with the known tumor suppressor gene Tropomyosin-1 to promote cytoskeletal organization that leads to terminal differentiation [42-46]. Several genes within the 20q11-13 region have also been identified as potential oncogenes that become amplified in breast and bladder carcinogenesis [47,48] and may play a role in immortalization of human uroepithelial cells [49]. However, the specific role of these genes in cancer development is not fully understood. Candidate gene studies on non-surgically removed RB eyes that include RB SCNAs, other non-highly recurrent SCNAs, and new alterations that arise longitudinally during therapy represent an interesting area of future study using the $\mathrm{AH}$ liquid biopsy platform to improve understanding of the broad clinical spectrum of RB.

Comprehensive RB SCNA analysis also provides the opportunity to investigate how genomics relate to clinical features and outcomes. While it is well established that a variety of clinical features affect ocular prognosis [28,30,50-53], it is not clear whether these clinical features are the result of a genetically 'high risk' RB, or if they arise independently of genomics. It bears emphasizing that the clinical characteristics were correlated to genomic alterations in $\mathrm{AH}$ samples taken both at time of diagnosis and at later stages throughout treatment. Preliminary data presented herein suggests that clinical features may be associated with RB genomics, however further study is needed before direct causality can be established. In general, eyes with more chromosomal instability displayed higher risk clinical features than eyes with less chromosomal instability. More advanced (IIRC Groups D and E) [30] eyes and eyes diagnosed at older ages tended to have more SCNAs than less advanced eyes and those diagnosed at younger ages. Accordingly, increased age at diagnosis has previously been associated with development of more advanced disease [54]. Although prior studies have reported relationships between chromosomal instability and laterality as well as heritability $[6,16,33,55]$, we postulate that the differences in age at diagnosis, even when controlling for Group classification and heritability, remain the driving factor. This is supported by the finding that any differences in chromosomal stability based on laterality or heritability disappeared when controlling for age at diagnosis. 
Consistent with previously published work [11,24], this suggests that the number of SCNAs a tumor develops is dependent on the length of time from initial tumorigenesis (biallelic RB1 loss or RB1-null cone precursor proliferation) to diagnosis. Interestingly, eyes with $6 \mathrm{p}$ gain, a biomarker of poor ocular prognosis, $[20,22]$ display more SCNAs than eyes without $6 \mathrm{p}$ gain, suggesting that once bi-allelic loss of $R B 1$ initiates genomic instability within a cell, $6 \mathrm{p}$ gain may be the first large-scale genomic change that occurs; this may lead to further chromosomal instability. However, the mechanism by which this occurs is not yet clear. Prior studies have identified E2F3 and DEK as candidate genes in the 6p minimum region of gain $[3,9,11,20,22]$. DEK encodes a DNA-binding protein that is a known oncogene in multiple other cancers [56,57], while E2F3 is crucial for transcriptional cell cycle control and is regulated by the RB protein $\mathrm{pRB}$ [58].

In terms of seeding, eyes with cloud or sphere morphologies displayed significantly more chromosomal instability than eyes with dust or no seeding. Cloud and sphere morphologies are higher risk, as eyes with these seeding patterns demonstrate poorer outcomes than those with dust or no seeding $[28,53]$. Differing chromosomal stability observed among seeding morphologies could be due to their underlying histopathologic differences. Cloud seeds are known to be largely necrotic, thus likely releasing high amounts of ctDNA, while sphere seeds contain several layers of viable tumor cells that can undergo clonal evolution and contribute to higher SCNA counts [59]. However, the seeding morphology a tumor develops could also be driven by RB genomics. We previously demonstrated that each increase in seeding class (from none to dust, from dust to sphere, and sphere to cloud) was significantly associated with two-fold increased odds of having $6 \mathrm{p}$ gain, an SCNA that multiple studies have theorized to be an important driver of RB tumorigenesis and aggressive disease [3,20,22]. Although 16q loss has previously been associated with the presence of seeding [60], implicating a functional role for cadherin 13 or cadherin 11 [61] which promotes cellular adhesion, this association with 16q loss was not observed in this comprehensive analysis. This may be due to the fact that enucleated eyes are a different cohort than the eyes included herein and likely have a larger seeding burden than eyes undergoing salvage. Larger studies with the statistical power to control for underlying genomic differences are needed to clarify the relationship between genomics and seeding morphology.

This comprehensive analysis also revealed that eyes with an endophytic tumor growth pattern (i.e., without retinal detachment) showed more chromosomal instability than eyes with retinal detachment, or with an exophytic tumor growth pattern. This did not remain significant when controlling for seeding, as endophytic RB tumors have a higher risk of seeding into the vitreous than exophytic tumors [62]. In addition to the contribution of seeding, the pathophysiology underlying this finding may be the death of normal retina cells that occurs during retinal detachment; the subsequent lysis of these cells causes the release of cell-free DNA (cfDNA) that is not tumor-derived, thus potentially diluting the tumor fraction below the assay's sensitivity. However, even if the primary tumor decreases in size, the tumor fraction can remain high in the presence of active seeding [21]. Future study with cfDNA quantification and fragment size analysis is encouraged to further elucidate the relationship between tumor growth pattern and SCNA development.

Our previously published work showed high concordance between tumor tissue and $\mathrm{AH}$ as well as overall stability of AH SCNA profiles within the same eye during intravitreal chemotherapy treatment $[20,22]$. This comprehensive analysis shows that a small number of eyes gained additional SCNAs seen at the time of secondary enucleation when compared to samples taken from the same eye during earlier conservative management. This increased chromosomal instability at time of secondary enucleation may reflect clonal evolution of the tumor, with newly arising SCNAs potentially indicating genes that proffer treatment resistance and signaling a worsening prognosis for these eyes. However, it is also possible that the tumor fraction in the first $\mathrm{AH}$ samples for these eyes (particularly cases 11,15 , and 17, with no SCNAs identified in their first samples which were taken during IVM treatment) was too low for SCNA detection given treatment response, as we have 
previously demonstrated that low tumor fraction correlates with disease regression [25]. Conversely, we have also shown that approximately one-third of RB tumors do not display SCNAs when AH is sampled during IVM $[20,22,25]$. Our recent publication evaluated AH samples taken at time of diagnosis [21], with a significantly higher concentration of cfDNA than $\mathrm{AH}$ samples taken during treatment, and found that three out of seven eyes demonstrated no detectable large scale SCNAs even at diagnosis. Thus, it may still be that cases 11, 15, and 17 truly did not display any tumoral SCNAs at time of initial AH sampling. With regard to case 33, the first $\mathrm{AH}$ sample was taken at time of diagnosis, when ctDNA concentrations are usually highest [21]. The presence of ctDNA in case $33^{\prime} \mathrm{s}$ first sample is confirmed by the four SCNAs seen in this genomic profile. With this in mind, the additional SCNAs of $2 p$ gain and $19 q$ loss in case $33^{\prime}$ s secondary enucleation sample offer future targets of study for molecular treatment resistance. There were also differences in SCNAs between primarily and secondarily enucleated eyes, which may suggest alterations conferred during the course of therapy. In particular, $8 p$ loss and $20 \mathrm{q}$ gain, seen almost exclusively in secondarily enucleated eyes, represent interesting targets of study for treatment resistance genes if proven to be present at statistically significant increased rates (Figure 3). Alterations in chromosome 8 are rarely reported in the literature, but 20q gain has been seen both in RB [16,63] and other cancers [64]. Further studies with longitudinal evaluation of the AH ctDNA from diagnosis throughout treatment will allow us to better clarify these findings.

$M Y C N$ driven tumors remain of interest to the RB community, given that they are described to be aggressive and non-responsive to treatment particularly in the setting of wild type RB1 (i.e., no RB1 mutation) [14,65]. In this study population, we present four eyes (Cases 3, 10, 31, and 48) with $M Y C N$ amplification identified; all four eyes were enucleated. Focal MYCN amplification in the setting of biallelic RB1 inactivation has been previously described $[41,65-68]$ and can be seen in case 10 of this study population (germline RB1 mutation). Although additional SCNAs in $M Y C N$ driven tumors are rare [14,69], cases 3 and 48 displayed highly recurrent RB SCNAS (plus 16p loss in case 3) in addition to $M Y C N$ amplification. Longitudinal samples within more $M Y C N$ eyes would be helpful to better understand the genomic basis of both the rare, primarily $M Y C N$-driven tumors in the setting of wild-type RB, as well as 'secondary' MYCN amplification in the setting of RB1 loss. This includes whether the development of additional SCNAs portends any increased risk to these eyes. Regardless, the potential utility of applying the AH liquid biopsy to identifying $M Y C N$ driven tumors at diagnosis remains clear.

\section{Conclusions}

We present the first comprehensive, genome-wide analysis of RB eyes using the AH liquid biopsy, along with a preliminary investigation into the relationships between RB genomics, clinical features, and outcomes. Compared to past publications, identification of these alterations via the $\mathrm{AH}$ liquid biopsy platform allows for a more comprehensive analysis as it includes not only enucleated eyes, but also less advanced eyes that have been salvaged and longitudinal evaluation during therapy. Furthermore, this allows for the detection of changes longitudinally during treatment such as new alterations at the time of secondary enucleation. In general, eyes with high chromosomal instability tended to have more advanced seeding morphologies, significantly larger tumor heights, significantly older ages at diagnosis, and were significantly more likely to demonstrate $6 \mathrm{p}$ gain, a biomarker of poor ocular prognosis. We emphasize that further studies-including more eyes and across multiple treatment centers-are needed before the AH liquid biopsy can be clinically applied and in order to clarify many of the associations reported here with statistical significance. In addition to advancing understanding of the RB genomic landscape, potential applications of the $\mathrm{AH}$ liquid biopsy include guiding clinical decision making and the opportunity to provide precision cancer care to RB patients in the future. 


\section{Patents}

Drs. Berry, Xu, and Hicks have filed a patent application entitled, Aqueous Humor Cell Free DNA for Diagnostic and Prognostic Evaluation of Ophthalmic Disease.

Supplementary Materials: The following are available online at https:/ / www.mdpi.com/article/ 10.3390 / cancers13133340/s1, Figure S1: Demographic and Diagnostic Patient Information, Figure S2: Genomic Information.

Author Contributions: Conceptualization, M.E.K., A.P., L.X., J.L.B.; Methodology, L.X., R.K.P., C.C.P., P.K., D.C., J.L.B.; Software, R.K.P.; Validation, L.X., R.S., J.L.B.; Formal Analysis, M.E.K., A.P., L.X., R.K.P., C.-C.P., M.W.R., J.L.B.; Investigation, M.E.K., A.P., L.X., C.-C.P., J.L.B.; Resources, L.X., P.K., D.C., J.H., J.L.B.; Data Curation, A.P., L.X., M.E.K., R.K.P., J.L.B.,; Writing-Original Draft Preparation, M.E.K., A.P., J.L.B.; Writing-Review and Editing, all authors; Visualization, M.E.K., A.P.; Supervision, L.X., P.K., D.C., J.H., J.L.B.; Project Administration, M.E.K., A.P., L.X., J.L.B.; Funding Acquisition, M.E.K., A.P., J.L.B. All authors have read and agreed to the published version of the manuscript.

Funding: This research was funded by Wright Foundation, National Cancer Institute of the National Institute of Health Award K08CA232344, National Institute of Health P30EY029220, National Cancer Institute P30CA014089, Hyundai Hope on Wheels RGA012351, Childhood Eye Cancer Trust, Knights Templar Eye Foundation, Institute for Families, Inc., Children's Hospital Los Angeles, Larry and Celia Moh Foundation, Nautica Foundation, Research to Prevent Blindness, an unrestricted departmental grant, USC Dornsife College of Letters, Arts and Sciences, Vicky Joseph Research Fund, and Carol Vassiliadis Research Fund. The funders had no role in the design of the study; in the collection, analyses, or interpretation of data; in the writing of the manuscript, or in the decision to publish the results.

Institutional Review Board Statement: The study was conducted according to the guidelines of the Declaration of Helsinki and approved by the Institutional Review Board of Children's Hospital Los Angeles (protocol code CHLA-17-00248, most recently re-approved 04/14/2021).

Informed Consent Statement: Written informed consent was obtained from legal guardians of all subjects involved in the study.

Data Availability Statement: The data presented in this study will be available on request from the corresponding author. Due to NIH funding, the data will be available to other researchers via NIH GDS/dbGAP controlled databases and will also be available to the public upon request from the corresponding author.

Acknowledgments: The authors would like to acknowledge the entire RB team for their support of this research, especially Kathy Anulao, ophthalmology nurse practitioner, Sarah Green, oncology nurse practitioner, and Team RAPIDO: Brianne Brown, Subramanian Krishnan, Dilshad Contractor \& Armine Begijanmasihi. It takes a village, and we thank you.

Conflicts of Interest: J.L.B., L.X., and J.H. have filed a provisional patent application entitled, Aqueous Humor Cell Free DNA for Diagnostic and Prognostic Evaluation of Ophthalmic Disease. Otherwise, the authors declare no potential conflicts of interest.

\section{References}

1. Parkin, D.M.; Stiller, C.A.; Draper, G.J.; Bieber, C.A. The international incidence of childhood cancer. Int. J. Cancer 1988, 42, 511-520. [CrossRef] [PubMed]

2. Donaldson, S.S.; Smith, L.M. Retinoblastoma: Biology, presentation, and current management. Oncology 1989, 3, $45-51$.

3. Corson, T.W.; Gallie, B.L. One hit, two hits, three hits, more? Genomic changes in the development of retinoblastoma. Genes Chromosomes Cancer 2007, 46, 617-634. [CrossRef]

4. Dimaras, H.; Khetan, V.; Halliday, W.; Orlic, M.; Prigoda, N.L.; Piovesan, B.; Marrano, P.; Corson, T.W.; Eagle Jr, R.C.; Squire, J.A. Loss of RB1 induces non-proliferative retinoma: Increasing genomic instability correlates with progression to retinoblastoma. Hum. Mol. Genet. 2008, 17, 1363-1372. [CrossRef] [PubMed]

5. Sampieri, K.; Mencarelli, M.A.; Carmela Epistolato, M.; Toti, P.; Lazzi, S.; Bruttini, M.; Francesco, S.D.; Longo, I.; Meloni, I.; Mari, F. Genomic differences between retinoma and retinoblastoma. Acta Oncol. 2008, 47, 1483-1492. [CrossRef]

6. Sampieri, K.; Amenduni, M.; Papa, F.T.; Katzaki, E.; Mencarelli, M.A.; Marozza, A.; Epistolato, M.C.; Toti, P.; Lazzi, S.; Bruttini, M. Array comparative genomic hybridization in retinoma and retinoblastoma tissues. Cancer Sci. 2009, 100, 465-471. [CrossRef] 
7. Singh, H.P.; Wang, S.; Stachelek, K.; Lee, S.; Reid, M.W.; Thornton, M.E.; Craft, C.M.; Grubbs, B.H.; Cobrinik, D. Developmental stage-specific proliferation and retinoblastoma genesis in RB-deficient human but not mouse cone precursors. Proc. Natl. Acad. Sci. USA 2018, 115, E9391-E9400. [CrossRef]

8. Gallie, B.L.; Campbell, C.; Devlin, H.; Duckett, A.; Squire, J.A. Developmental basis of retinal-specific induction of cancer by RB mutation. Cancer Res. 1999, 59, 1731s-1735s.

9. Bowles, E.; Corson, T.W.; Bayani, J.; Squire, J.A.; Wong, N.; Lai, P.B.S.; Gallie, B.L. Profiling genomic copy number changes in retinoblastoma beyond loss of RB1. Genes Chromosomes Cancer 2007, 46, 118-129. [CrossRef]

10. Kooi, I.E.; Mol, B.M.; Massink, M.P.G.; Ameziane, N.; Meijers-Heijboer, H.; Dommering, C.J.; Van Mil, S.E.; De Vries, Y.; Van Der Hout, A.H.; Kaspers, G.J.L. Somatic genomic alterations in retinoblastoma beyond RB1 are rare and limited to copy number changes. Sci. Rep. 2016, 6, 1-11. [CrossRef]

11. Kooi, I.E.; Mol, B.M.; Massink, M.P.G.; de Jong, M.C.; de Graaf, P.; van der Valk, P.; Meijers-Heijboer, H.; Kaspers, G.J.L.; Moll, A.C.; Te Riele, H. A meta-analysis of retinoblastoma copy numbers refines the list of possible driver genes involved in tumor progression. PLoS ONE 2016, 11, e0153323. [CrossRef]

12. Grasemann, C.; Gratias, S.; Stephan, H.; Schüler, A.; Schramm, A.; Klein-Hitpass, L.; Rieder, H.; Schneider, S.; Kappes, F.; Eggert, A. Gains and overexpression identify DEK and E2F3 as targets of chromosome 6p gains in retinoblastoma. Oncogene 2005, 24, 6441-6449. [CrossRef]

13. Cobrinik, D. Retinoblastoma progression. EBioMedicine 2015, 2, 623-624. [CrossRef]

14. Rushlow, D.E.; Mol, B.M.; Kennett, J.Y.; Yee, S.; Pajovic, S.; Thériault, B.L.; Prigoda-Lee, N.L.; Spencer, C.; Dimaras, H.; Corson, T.W. Characterisation of retinoblastomas without RB1 mutations: Genomic, gene expression, and clinical studies. Lancet Oncol. 2013, 14, 327-334. [CrossRef]

15. Thériault, B.L.; Dimaras, H.; Gallie, B.L.; Corson, T.W. The genomic landscape of retinoblastoma: A review. Clin. Exp. Ophthalmol. 2014, 42, 33-52. [CrossRef]

16. van der Wal, J.E.; Hermsen, M.A.J.A.; Gille, H.J.P.; Schouten-Van Meeteren, N.Y.N.; Moll, A.C.; Imhof, S.M.; Meijer, G.A.; Baak, J.P.A.; van der Valk, P. Comparative genomic hybridisation divides retinoblastomas into a high and a low level chromosomal instability group. J. Clin. Pathol. 2003, 56, 26. [CrossRef] [PubMed]

17. Karcioglu, Z.A.; Gordon, R.A.; Karcioglu, G.L. Tumor seeding in ocular fine needle aspiration biopsy. Ophthalmology 1985, 92, 1763-1767. [CrossRef]

18. Shields, J.A.; Shields, C.L.; Ehya, H.; Eagle Jr, R.C.; Patrick De Potter, M.D. Fine-needle aspiration biopsy of suspected intraocular tumors: The 1992 Urwick lecture. Ophthalmology 1993, 100, 1677-1684. [CrossRef]

19. Berry, J.L.; Xu, L.; Murphree, A.L.; Krishnan, S.; Stachelek, K.; Zolfaghari, E.; McGovern, K.; Lee, T.C.; Carlsson, A.; Kuhn, P.; et al. Potential of aqueous humor as a surrogate tumor biopsy for retinoblastoma. JAMA Ophthalmol. 2017, 135, 1221-1230. [CrossRef] [PubMed]

20. Berry, J.L.; Xu, L.Y.; Kooi, I.; Murphree, A.L.; Prabakar, R.K.; Reid, M.; Stachelek, K.; Le, B.H.A.; Welter, L.; Reiser, B.J.; et al. Genomic cfDNA analysis of aqueous humor in retinoblastoma predicts eye salvage: The surrogate tumor biopsy for retinoblastoma. Mol. Cancer Res. 2018, 16, 701-1712. [CrossRef]

21. Xu, L.; Kim, M.E.; Polski, A.; Prabakar, R.K.; Shen, L.; Peng, C.-C.; Reid, M.W.; Chévez-Barrios, P.; Kim, J.W.; Shah, R.; et al. Establishing the clinical utility of ctDNA analysis for diagnosis, prognosis, and treatment monitoring of retinoblastoma: The aqueous humor liquid biopsy. Cancers 2021, 13, 1282. [CrossRef]

22. Xu, L.; Polski, A.; Prabakar, R.K.; Reid, M.W.; Chevez-Barrios, P.; Jubran, R.; Kim, J.W.; Kuhn, P.; Cobrinik, D.; Hicks, J.; et al. Chromosome $6 \mathrm{p}$ amplification in aqueous humor cell-free DNA is a prognostic biomarker for retinoblastoma ocular survival. Mol. Cancer Res. 2020, 18, 1166-1175. [CrossRef]

23. Berry, J.L.; Xu, L.; Polski, A.; Jubran, R.; Kuhn, P.; Kim, J.W.; Hicks, J. Aqueous humor is superior to blood as a liquid biopsy for retinoblastoma. Ophthalmology 2020, 127, 552-554. [CrossRef]

24. Polski, A.; Xu, L.; Prabakar, R.K.; Gai, X.; Kim, J.W.; Shah, R.; Jubran, R.; Kuhn, P.; Cobrinik, D.; Hicks, J.; et al. Variability in retinoblastoma genome stability is driven by age and not heritability. Genes Chromosomes Cancer 2020, 59, 584-590. [CrossRef]

25. Polski, A.; Xu, L.; Prabakar, R.; Kim, J.W.; Cobrinik, D.; Hicks, J.; Berry, J.L. Longitudinal aqueous humor sampling reflects treatment response in retinoblastoma patients. Investig. Ophthalmol. Vis. Sci. 2020, 61, 1394.

26. Xu, L.; Shen, L.; Polski, A.; Prabakar, R.K.; Shah, R.; Jubran, R.; Kim, J.W.; Biegel, J.; Kuhn, P.; Cobrinik, D.; et al. Simultaneous identification of clinically relevant RB1 mutations and copy number alterations in aqueous humor of retinoblastoma eyes. Ophthalmic Genet. 2020, 41, 526-532. [CrossRef]

27. Berry, J.L.; Jubran, R.; Kim, J.W.; Wong, K.; Bababeygy, S.R.; Almarzouki, H.; Lee, T.C.; Murphree, A.L. Long-term outcomes of Group D eyes in bilateral retinoblastoma patients treated with chemoreduction and low-dose IMRT salvage. Pediatric Blood Cancer 2013, 60, 688-693. [CrossRef]

28. Berry, J.L.; Bechtold, M.; Shah, S.; Zolfaghari, E.; Reid, M.; Jubran, R.; Kim, J.W. Not all seeds are created equal: Seed classification is predictive of outcomes in retinoblastoma. Ophthalmology 2017, 124, 1817-1825. [CrossRef]

29. Berry, J.L.; Kogachi, K.; Aziz, H.A.; McGovern, K.; Zolfaghari, E.; Murphree, A.L.; Jubran, R.; Kim, J.W. Risk of metastasis and orbital recurrence in advanced retinoblastoma eyes treated with systemic chemoreduction versus primary enucleation. Pediatric Blood Cancer 2017, 64, e26270. [CrossRef]

30. Linn, A.M. Intraocular retinoblastoma: The case for a new group classification. Ophthalmol. Clin. N. Am. 2005, 18, 41-53. 
31. Baslan, T.; Kendall, J.; Rodgers, L.; Cox, H.; Riggs, M.; Stepansky, A.; Troge, J.; Ravi, K.; Esposito, D.; Lakshmi, B. Genome-wide copy number analysis of single cells. Nat. Protoc. 2012, 7, 1024-1041. [CrossRef] [PubMed]

32. Baslan, T.; Kendall, J.; Rodgers, L.; Cox, H.; Riggs, M.; Stepansky, A.; Troge, J.; Ravi, K.; Esposito, D.; Lakshmi, B. Erratum: Genome-wide copy number analysis of single cells. Nat. Protoc. 2016, 11. [CrossRef]

33. Zielinski, B.; Gratias, S.; Toedt, G.; Mendrzyk, F.; Stange, D.E.; Radlwimmer, B.; Lohmann, D.R.; Lichter, P. Detection of chromosomal imbalances in retinoblastoma by matrix-based comparative genomic hybridization. Genes Chromosomes Cancer 2005, 43, 294-301. [CrossRef] [PubMed]

34. Gröbner, S.N.; Worst, B.C.; Weischenfeldt, J.; Buchhalter, I.; Kleinheinz, K.; Rudneva, V.A.; Johann, P.D.; Balasubramanian, G.P.; Segura-Wang, M.; Brabetz, S.; et al. The landscape of genomic alterations across childhood cancers. Nature 2018, 555, 321-327. [CrossRef] [PubMed]

35. Zack, T.I.; Schumacher, S.E.; Carter, S.L.; Cherniack, A.D.; Saksena, G.; Tabak, B.; Lawrence, M.S.; Zhsng, C.Z.; Wala, J.; Mermel, C.H.; et al. Pan-cancer patterns of somatic copy number alteration. Nat. Genet. 2013, 45, 1134-1140. [CrossRef] [PubMed]

36. Beroukhim, R.; Mermel, C.H.; Porter, D.; Wei, G.; Raychaudhuri, S.; Donovan, J.; Barretina, J.; Boehm, J.S.; Dobson, J.; Urashima, M.; et al. The landscape of somatic copy-number alteration across human cancers. Nature 2010, 463, 899-905. [CrossRef] [PubMed]

37. Yuan, X.; Larsson, C.; Xu, D. Mechanisms underlying the activation of TERT transcription and telomerase activity in human cancer: Old actors and new players. Oncogene 2019, 38, 6172-6183. [CrossRef] [PubMed]

38. Hanahan, D.; Weinberg, R.A. Hallmarks of cancer: The next generation. Cell 2011, 144, 646-674. [CrossRef]

39. Shay, J.W.; Wright, W.E. Telomeres and telomerase: Three decades of progress. Nat. Rev. Genet. 2019, 20, 299-309. [CrossRef]

40. Seluanov, A.; Gladyshev, V.N.; Vijg, J.; Gorbunova, V. Mechanisms of cancer resistance in long-lived mammals. Nat. Rev. Cancer 2018, 18, 433-441. [CrossRef]

41. Francis, J.H.; Richards, A.L.; Mandelker, D.L.; Berger, M.F.; Walsh, M.F.; Dunkel, I.J.; Donoghue, M.T.A.; Abramson, D.H. Molecular changes in retinoblastoma beyond RB1: Findings from next-generation sequencing. Cancers 2021, 13, 149. [CrossRef]

42. Mlakar, V.; Berginc, G.; Volavšek, M.; Štor, Z.; Rems, M.; Glavač, D. Presence of activating KRAS mutations correlates significantly with expression of tumour suppressor genes DCN and TPM1 in colorectal cancer. BMC Cancer 2009, 9, 1-9. [CrossRef]

43. Pan, H.; Gu, L.; Liu, B.; Li, Y.; Wang, Y.; Bai, X.; Li, L.; Wang, B.; Peng, Q.; Yao, Z. Tropomyosin-1 acts as a potential tumor suppressor in human oral squamous cell carcinoma. PLoS ONE 2017, 12, e0168900. [CrossRef] [PubMed]

44. Wang, J.; Tang, C.; Yang, C.; Zheng, Q.; Hou, Y. Tropomyosin-1 functions as a tumor suppressor with respect to cell proliferation, angiogenesis and metastasis in renal cell carcinoma. J. Cancer 2019, 10, 2220. [CrossRef]

45. Hu, J.; Ho, A.L.; Yuan, L.; Hu, B.; Hua, S.; Hwang, S.S.; Zhang, J.; Hu, T.; Zheng, H.; Gan, B. Neutralization Termin. Differ. gliomagenesis. Proc. Natl. Acad. Sci. USA 2013, 110, 14520-14527. [CrossRef]

46. Bharadwaj, S.; Prasad, G.L. Tropomyosin-1, a novel suppressor of cellular transformation is downregulated by promoter methylation in cancer cells. Cancer Lett. 2002, 183, 205-213. [CrossRef]

47. Collins, C.; Rommens, J.M.; Kowbel, D.; Godfrey, T.; Tanner, M.; Hwang, S.I.; Polikoff, D.; Nonet, G.; Cochran, J.; Myambo, K.; et al. Positional cloning of ZNF217 and NABC1: Genes amplified at 20q13.2 and overexpressed in breast carcinoma. Proc. Natl. Acad. Sci. USA 1998, 95, 8703-8708. [CrossRef]

48. Guo, Z.; Linn, J.F.; Wu, G.; Anzick, S.L.; Eisenberger, C.F.; Halachmi, S.; Cohen, Y.; Fomenkov, A.; Hoque, M.O.; Okami, K.; et al. CDC91L1 (PIG-U) is a newly discovered oncogene in human bladder cancer. Nat. Med. 2004, 10, 374-381. [CrossRef] [PubMed]

49. Cuthill, S.; Agarwal, P.; Sarkar, S.; Savelieva, E.; Reznikoff, C.A. Dominant genetic alterations in immortalization: Role for 20q gain. Genes Chromosomes Cancer 1999, 26, 304-311. [CrossRef]

50. Chantada, G.L.; Gonzalez, A.; Fandino, A.; de Davila, M.T.; Demirdjian, G.; Scopinaro, M.; Abramson, D. Some clinical findings at presentation can predict high-risk pathology features in unilateral retinoblastoma. J. Pediatric Hematol. Oncol. 2009, 31, 325-329. [CrossRef]

51. Chawla, B.; Sharma, S.; Sen, S.; Azad, R.; Bajaj, M.S.; Kashyap, S.; Pushker, N.; Ghose, S. Correlation between clinical features, magnetic resonance imaging, and histopathologic findings in retinoblastoma: A prospective study. Ophthalmology 2012, 119, 850-856. [CrossRef] [PubMed]

52. Kaliki, S.; Srinivasan, V.; Gupta, A.; Mishra, D.K.; Naik, M.N. Clinical features predictive of high-risk retinoblastoma in 403 Asian Indian patients: A case-control study. Ophthalmology 2015, 122, 1165-1172. [CrossRef]

53. Francis, J.H.; Abramson, D.H.; Gaillard, M.-C.; Marr, B.P.; Beck-Popovic, M.; Munier, F.L. The classification of vitreous seeds in retinoblastoma and response to intravitreal melphalan. Ophthalmology 2015, 122, 1173-1179. [CrossRef] [PubMed]

54. Kim, H.A.; Yoon, Y.H.; Kim, J.G.; Lee, J.Y. Clinical Features and Long-term Prognosis of Retinoblastoma according to Age at Diagnosis. Korean J Ophthalmol 2020, 34, 242-250. [CrossRef] [PubMed]

55. Mol, B.M.; Massink, M.P.G.; van der Hout, A.H.; Dommering, C.J.; Zaman, J.M.A.; Bosscha, M.I.; Kors, W.A.; Meijers-Heijboer, H.E.; Kaspers, G.J.L.; Riele, H.t. High resolution SNP array profiling identifies variability in retinoblastoma genome stability. Genes Chromosomes Cancer 2014, 53, 1-14. [CrossRef]

56. Von Lindern, M.; Fornerod, M.; Soekarman, N.; Van Baal, S.; Jaegle, M.; Hagemeijer, A.; Bootsma, D.; Grosveld, G. Translocation $\mathrm{t}$ $(6 ; 9)$ in acute non-lymphocytic leukaemia results in the formation of a DEK-CAN fusion gene. Bailliere's Clin. Haematol. 1992, 5, 857-879. [CrossRef] 
57. Carro, M.S.; Spiga, F.M.; Quarto, M.; Ninni, V.D.; Volorio, S.; Alcalay, M.; Müller, H. DEK expression is controlled by E2F and deregulated in diverse tumor type. Cell Cycle 2006, 5, 1202-1207. [CrossRef]

58. Adams, M.R.; Sears, R.; Nuckolls, F.; Leone, G.; Nevins, J.R. Complex transcriptional regulatory mechanisms control expression of the E2F3 locus. Mol. Cell. Biol. 2000, 20, 3633-3639. [CrossRef]

59. Amram, A.L.; Rico, G.; Kim, J.W.; Chintagumpala, M.; Herzog, C.E.; Gombos, D.S.; Chévez-Barrios, P. Vitreous seeds in retinoblastoma: Clinicopathologic classification and correlation. Ophthalmology 2017, 124, 1540-1547. [CrossRef]

60. Gustmann, S.; Klein-Hitpass, L.; Stephan, H.; Weber, S.; Bornfeld, N.; Kaulisch, M.; Lohmann, D.R.; Dunker, N. Loss at chromosome arm 16q in retinoblastoma: Confirmation of the association with diffuse vitreous seeding and refinement of the recurrently deleted region. Genes Chromosomes Cancer 2011, 50, 327-337. [CrossRef]

61. Marchong, M.N.; Chen, D.; Corson, T.W.; Lee, C.; Harmandayan, M.; Bowles, E.; Chen, N.; Gallie, B.L. Minimal 16q genomic loss implicates cadherin-11 in retinoblastoma. Mol. Cancer Res. 2004, 2, 495-503. [PubMed]

62. Nawaiseh, I.; Al-Hussaini, M.; Alhamwi, A.; Meyar, M.; Sultan, I.; Alrawashdeh, K.; Jaradat, I.; Yousef, Y.A. The impact of growth patterns of retinoblastoma (endophytic, exophytic, and mixed patterns). Turk. Patoloji. Derg. 2015, 31, 45-50. [CrossRef] [PubMed]

63. Kim, J.H.; Kim, J.H.; Yu, Y.S.; Kim, D.H.; Kim, Y.K.; Kim, K.-W. Comparative genomic hybridization analysis of newly established retinoblastoma cell lines of adherent growth compared with Y79 of nonadherent growth. J. Pediatric Hematol. Oncol. 2008, 30, 571-574. [CrossRef] [PubMed]

64. Klingelhutz, A.J.; Qian, Q.; Phillips, S.L.; Gourronc, F.A.; Darbro, B.W.; Patil, S.R. Amplification of the chromosome 20q region is associated with expression of HPV-16 E7 in human airway and anogenital epithelial cells. Virology 2005, 340, 237-244. [CrossRef]

65. Afshar, A.R.; Pekmezci, M.; Bloomer, M.M.; Cadenas, N.J.; Stevers, M.; Banerjee, A.; Roy, R.; Olshen, A.B.; Van Ziffle, J.; Onodera, C.; et al. Next generation sequencing of retinoblastoma identifies pathogenic alterations beyond RB1 inactivation that correlate with aggressive histopathologic features. Ophthalmology 2020, 127, 804-813. [CrossRef]

66. Fabian, I.D.; Abdallah, E.; Abdullahi, S.U.; Abdulqader, R.A.; Boubacar, S.A.; Ademola-Popoola, D.S.; Adio, A.; Afshar, A.R.; Aggarwal, P.; Aghaji, A.E. Global retinoblastoma presentation and analysis by national income level. JAMA Oncol. 2020, 6, 685-695.

67. Schwermer, M.; Hiber, M.; Dreesmann, S.; Rieb, A.; Theißen, J.; Herold, T.; Schramm, A.; Temming, P.; Steenpass, L. Comprehensive characterization of RB1 mutant and MYCN amplified retinoblastoma cell lines. Exp. Cell. Res. 2019, 375, 92-99. [CrossRef]

68. Davies, H.R.; Broad, K.D.; Onadim, Z.; Price, E.A.; Zou, X.; Sheriff, I.; Karaa, E.K.; Scheimberg, I.; Reddy, M.A.; Sagoo, M.S. Wholegenome sequencing of retinoblastoma reveals the diversity of rearrangements disrupting RB1 and uncovers a treatment-related mutational signature. Cancers 2021, 13, 754. [CrossRef]

69. Lillington, D.M.; Kingston, J.E.; Coen, P.G.; Price, E.; Hungerford, J.; Domizio, P.; Young, B.D.; Onadim, Z. Comparative genomic hybridization of 49 primary retinoblastoma tumors identifies chromosomal regions associated with histopathology, progression, and patient outcome. Genes Chromosomes Cancer 2003, 36, 121-128. [CrossRef] [PubMed] 